\title{
LINFOSSARCOMA EM CÃES
}

\author{
LYMPHOSARCOMA IN DOGS
}

\author{
Rafael Almeida Fighera ${ }^{1}$ Tatiana Mello de Souza ${ }^{2}$ \\ Claudio Severo Lombardo de Barros ${ }^{33}$
}

\section{- REVISÃO BIBLIOGRÁFICA -}

\section{RESUMO}

\begin{abstract}
O linfossarcoma é uma neoplasia linfóide que se origina em órgão sólido e que, em cães, não tem ainda uma etiologia determinada. O diagnóstico dessa neoplasia pode ser feito tanto por citologia como por histopatologia, embora, muitas vezes, sua diferenciação de leucemia linfóide seja difícil. Vários sinais clínicos são associados com o linfossarcoma canino, a maioria deles relacionada ao órgão na qual o tumor se localiza. Uma manifestação comum é a linfadenopatia generalizada que deve ser diferenciada de outras enfermidades que causam aumento de volume dos linfonodos. Algumas síndromes paraneoplásicas complicam casos de linfossarcoma e, muitas vezes, são responsáveis pela morte do animal. Neste trabalho, são revisados os aspectos clínicos, laboratoriais, as alterações de necropsia e histopatologia do linfossarcoma canino.
\end{abstract}

Palavras-chave: linfossarcoma, linfoma, oncologia, hematologia, doenças de cães.

\section{SUMMARY}

Lymphosarcomas are lymphoid neoplasms which arise in a solid organ and which, in dogs, have an yet undetermined etiology. A lymphosarcoma can be diagnosed both by cytology and histopathology, although often its differentiation from lymphoid leukemia can be difficult. Several signs are associated with canine lymphosarcomas and they vary according to the compromised organ. A common manifestation is generalized lymphadenopathy which should be differentiated from other diseases that cause enlargement of lymphnodes. Some paraneopastic syndromes may compound cases of lymphosarcoma and are often the cause of the animal's death. This paper reviews the clinical, laboratorial, gross and histopathological aspects of canine lymphosarcoma.
Key words: lymphosarcoma, lymphoma, oncology, hematology, diseases of dogs.

\section{INTRODUÇÃO}

O linfoma ou linfossarcoma é o tumor linfóide que se origina em órgão hematopoético sólido, como linfonodo, baço ou fígado (COUTO, 1992). Essa é a neoplasia hematopoética mais comumente relatada em cães, perfazendo aproximadamente $90 \%$ dos casos, com prevalência anual de 24/100.000 (MOULTON \& HARVEY, 1990). A distinção entre linfoma e leucemia linfóide é, muitas vezes, difícil, ou até mesmo impossível em alguns casos. Quando há infiltração da medula óssea, a aparência é indistingüível nas duas condições, já que não se pode saber se a proliferação iniciou nesse local ou apenas metastatizou para ele (LEIFER \& MATUS, 1986; RAPAPORT, 1990b).

As células neoplásicas têm, freqüentemente, características morfológicas de um dos estádios de ativação ou transformação que a célula sofre após exposição ao antígeno, ou seja, são grandes linfócitos, alguns em mitose, com núcleos duplos e nucléolos evidentes (RAPAPORT, 1990b). Os linfomas caninos são, na maioria das vezes, originários de linfócitos $\mathrm{B}$, ao contrário do que

${ }^{1}$ Médico Veterinário, Bolsista de apoio técnico do CNPq. Seção de Patologia Veterinária. Universidade Federal de Santa Maria (UFSM), 97105-900, Santa Maria, RS. E-mail: anemiaveterinaria@bol.com.br. Autor para correspondência.

${ }^{2}$ Médico Veterinário Autônomo, Santa Maria, RS.

${ }^{3}$ Médico Veterinário, PhD., Professor Titular do Departamento de Patologia, UFSM

Recebido para publicação em 17.07.01. Aprovado em 05.12.01 
ocorre em felinos infectados pelo vírus da leucemia felina, nos quais os linfomas são oriundos de células T (VALLI, 1993).

As várias classificações propostas para o linfoma humano, são utilizadas também para cães, embora não rotineiramente. Dentre elas, destacam-se a de Rapaport e a de Lukes-Collins (WILCOCK \& YAGER, 1989). Nos humanos, o primeiro passo está em diferenciar entre linfoma de Hodgkin e nãoHodgkin (RAPAPORT, 1990a). A doença de Hodgkin é diagnosticada pela presença da célula de Reed-Sternberg, que é multinucleada, às vezes com núcleo com imagem em espelho, sendo que cada núcleo possui um nucléolo gigante (RAPAPORT, 1990a; BAIN, 1995). Essa forma ainda é insuficientemente descrita em cães (WELLS, 1974; MAEDA et al., 1993). Uma classificação de linfoma bastante utilizada em medicina veterinária é baseada na localização das massas tumorais, isto é: multicêntrico, mediastínico, alimentar e misto (MOULTON \& HARVEY, 1990).

A etiologia do linfoma canino tem sido exaustivamente investigada. Ao contrário do linfoma de felinos e bovinos, ele não é induzido por vírus (FIGHERA, 2000). Vários trabalhos foram realizados a fim de estabelecer a prevalência dessa neoplasia. Um deles utilizou 75 cães e mostrou que $20 \%$ dos animais tinham de 2 a 4 anos, 61,3\% tinham de 5 a 9 anos e 18,7\% tinham de 10 a 17 anos (JAIN, 1986).

\section{FORMA MULTICÊNTRICA}

O linfossarcoma multicêntrico acomete os linfonodos superficiais e profundos, o baço, o fígado, as tonsilas e a medula óssea, caracterizandose por linfadenopatia bilateral dos linfonodos superficiais, principalmente do poplíteo, mandibular, pré-escapular e axilar (GREENE, 1996; HARVEY, 1996). Nessa forma, podem ocorrer hepatomegalia e esplenomegalia (Figura 1), em consequiência da infiltração neoplásica (MOULTON \& HARVEY, 1990). Os sinais clínicos incluem anorexia, caquexia, desidratação, ascite, palidez das mucosas e icterícia (WILCOCK \& YAGER, 1989). O linfoma hepático corresponde a $63 \%$ dos tumores metastáticos do fígado e induz uma elevação de leve à moderada da atividade sérica da alanina aminotransferase em 46-70\% dos casos (MACLACHLAN \& CULLEN, 1998; FIGHERA, 2000). Quando o linfoma acomete o fígado, pode ocorrer icterícia pela hiperbilirrubinemia indireta e ascite pela hipoproteinemia (WILCOCK \& YAGER, 1989).
Muitas vezes, animais com a forma multicêntrica apresentam massas tumorais nos pulmões e coração (HAWKINS et al., 1992). Quando acomete os pulmões, a neoplasia aparece nas radiografias como uma área de densidade nodular mal definida, com padrão alveolar irregular, raramente como uma lesão única. Sendo assim, o diagnóstico radiográfico é difícil de ser feito, a não ser que a lesão esteja associada à linfadenopatia hilar, mediastínica ou esternal (ACKERMAN \& MADEWELL, 1980). Quando ocorre infiltração do miocárdio, os sinais se assemelham a várias afecções que induzem insuficiência cardíaca (VAN VLEET \& FERRANS, 1998).

Poucas entidades clínicas causam linfadenopatia generalizada a ponto de serem confundidas com linfoma multicêntrico, mas os diagnósticos diferenciais devem incluir histoplasmose, blastomicose, erliquiose, brucelose, mieloma múltiplo, leucemia linfóide e lúpus eritematoso sistêmico (GREENE, 1996).

\section{FORMA ALIMENTAR}

O linfossarcoma alimentar caracteriza-se pela presença da neoplasia no trato gastrointestinal e/ou nos linfonodos mesentéricos (WELLMAN, 1996). O linfoma acomete o intestino no "tecido linfóide associado ao intestino" (GALT), constituindo-se na segunda neoplasia mais comum de intestino em cães (10\% das neoplasias intestinais) perdendo apenas para o adenocarcinoma (FIGHERA, 2000).

Morfologicamente, o linfoma ocorre tanto na forma nodular como na forma difusa. $\mathrm{Na}$ forma difusa, há infiltração extensa da lâmina própria e submucosa, causando síndrome de má-absorção e conseqüentemente esteatorréia e diarréia (SHERDING, 1992). Na forma nodular, ocorre um espessamento segmentar do intestino, mais freqüentemente na região ileocecocólica que poderá causar estreitamento luminal e obstrução intestinal parcial (JONES et al., 2000). No intestino grosso, normalmente ocorre infiltração difusa da mucosa e ulceração, levando à melena (RICHTER, 1992). A neoplasia linfóide no estômago de cães é rara e parece ter prevalência maior em machos, ao contrário dos felinos nos quais o linfoma gástrico é o tumor de estômago mais comum (TWEDT \& MAGNE, 1992).

\section{FORMA MEDIASTÍNICA}

A forma mediastínica envolve o timo (forma tímica) e/ou os linfonodos mediastinais 


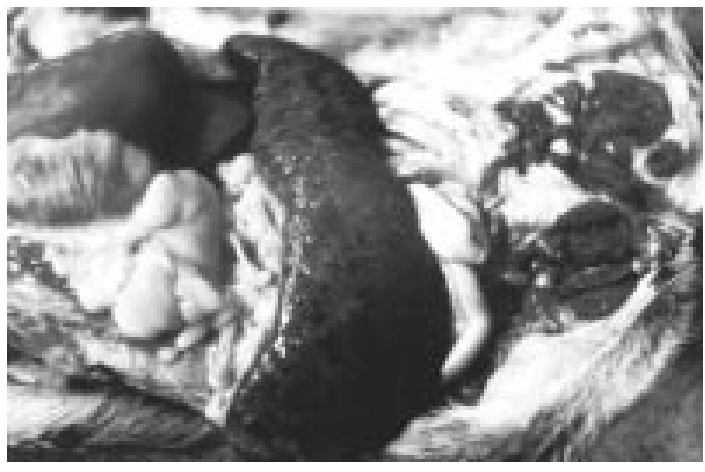

Figura 1 - Esplenomegalia oriunda da infiltração neoplásica em um cão com linfossarcoma multicêntrico.

anteriores e posteriores, caracterizando-se pelo aparecimento agudo de dispnéia, taquipnéia, tosse, regurgitação, anorexia, caquexia e letargia (BAUER, 1992). Os achados físicos incluem cianose, deslocamento dos ruídos cardíacos dorsocaudalmente, ausência de ruídos broncovesiculares e som maciço na percussão torácica (COUTO, 1992). Pode ainda ocorrer hemotórax com grande número de células linfóides vacuolizadas e quilotórax (FIGHERA, 2000).

Muitas vezes, na forma mediastínica, ocorre a chamada síndrome da veia cava, que se caracteriza por edema e tumefação simétrica da cabeça, pescoço e membros torácicos (BAUER, 1992). Este fenômeno está relacionado à hipertensão venosa e estase linfática, podendo também ocorrer nos membros pélvicos de animais com a forma multicêntrica (FIGHERA, 2000). A forma tímica é rara em caninos e deve ser diferenciada de timoma, carcinoma pulmonar hilar e adenocarcinoma ectópico da tireóide (BAUER, 1992).

\section{FORMA MISTA}

O linfoma misto corresponde à neoplasia extra-nodal que pode afetar qualquer tecido corpóreo, com várias manifestações clínicas (COUTO, 1992). Por exemplo, quando acomete o olho causa uveíte, glaucoma e hifema, já quando ocorre no cérebro leva à convulsão (WHITFORD, 1965; SLATTER, 1992). Na pele, o linfoma pode ser B ou T. Quando derivado de linfócitos T, ocorre como micose fungóide, síndrome de Sézari e reticulose pagetóide (WILKINSON \& HARVEY, 1996).

A micose fungóide é um distúrbio de progressão lenta que se mostra como erupção eritematosa pruriginosa descamativa inespecífica indistinguível de uma dermatose inflamatória
(FIGHERA, 2000). Após alguns meses formam-se placas firmes na porção superior da derme, comprimindo a epiderme ou infiltrando-a, formando agregados conhecidos como abscessos de Pautrier. As placas são constituídas de linfócitos, plasmócitos, histiócitos e eosinófilos. Os linfócitos são grandes, com núcleo contorcido (células de micose) (SCOTT et al., 1996). A síndrome de Sézari é mais agressiva e se caracteriza por eritroderma difuso, esfoliativo, pruriginoso e eritematoso. Os linfócitos nessa forma de linfoma são menores e têm o núcleo com inúmeras projeções digitiformes (células de Sézari) (THRALL et al., 1984).

Existem vários relatos de linfossarcoma cerebral e medular que, algumas vezes, podem ser primários. O linfoma pode ocorrer também em nervos periféricos e estender-se ao longo dos nervos espinhais e raízes nervosas até o canal medular, resultando em sinais clínicos de doença espinhal (FIGHERA, 2000).

$\mathrm{Na}$ cavidade nasal, o linfossarcoma é a afecção neoplásica mais comum, juntamente com carcinomas e com o tumor venéreo transmissível, induzindo sinais clínicos como dispnéia, epistaxe e corrimento nasal (BEDFORD, 1992). O linfoma renal em cães, ocorre com uma prevalência bem menor do que em gatos e leva à hematúria de origem renal, renomegalia e insuficiência renal quando o processo é bilateral (KRUGER \& OSBORNE, 1995).

\section{SÍNDROMES PARANEOPLÁSICAS}

A hipercalcemia é uma das síndromes paraneoplásicas mais bem descritas em medicina veterinária, sendo atribuída à liberação de fatores de reabsorção óssea, como o fator ativador de osteoclastos, por parte de linfócitos neoplásicos (COUTO, 1992). Essas proteínas estimulam a reabsorção óssea e renal do cálcio, de efeito semelhante ao paratormônio. Esses quadros de reabsorção óssea desencadeiam osteopenia, facilitando o aparecimento de fraturas (FIGHERA, 2000). A hipercalcemia leva ainda à hipercalciúria e conseqüente disfunção tubular renal e urolitíase (MEUTEN \& ARMSTRONG, 1992).

O linfoma, o mieloma múltiplo, o plasmocitoma, a leucemia linfocítica crônica e a macroglobulinemia primária (macroglobulinemia de Waldenström) são conhecidos como tumores secretores de imunoglobulina (RAPAPORT, 1990b). Essas imunoglobulinas são chamadas de paraproteínas ou componente $\mathrm{M}$ e podem ser $\mathrm{Ig}$ M, Ig $\mathrm{G}$ e Ig A. Quando produzidas em grandes quantidades, interferem na função plaquetária levando a trombocitopatias e inibem alguns fatores 
de coagulação, ocasionando diátese hemorrágica (BAIN, 1995). Clinicamente podem ocorrer epistaxe, sangramento gengival e gastrointestinal. As paraproteínas em excesso tornam o sangue mais viscoso e causam a chamada síndrome da hiperviscosidade que leva a distúrbios neurológicos, cardíacos e renais (FIGHERA, 2000).

Os pacientes com linfossarcoma comumente desenvolvem anemia de leve à moderada, decorrente da liberação de fatores neoplásicos que deprimem a eritropoese (anemia hipoplásica). A infiltração da medula óssea pelo tumor (Figura 2) pode ocasionar anemia mielotísica, agravando o processo. Outras formas de anemia são também descritas, dentre elas: anemia hemolítica auto-imune, anemia hemorrágica e anemia das doenças crônicas (FIGHERA, 2001).

\section{DIAGNóSTICO}

O diagnóstico do linfossarcoma é, na maioria das vezes, fácil de ser estabelecido, já que não há necessidade de exames complexos para sua realização (JAIN, 1986). A prevalência da linfadenomegalia em cães com linfoma é alta, fazendo desse aspecto o principal achado para determinação da suspeita clínica (GREENE, 1996). Sendo assim, todos os cães que apresentarem linfadenopatia generalizada devem ser submetidos à punção aspirativa por agulha fina (PAAF) a fim de ser realizado o exame citopatológico (COUTO, 1992).

$\mathrm{Na}$ maioria das vezes, os aspectos citológicos de linfonodos aspirados caracterizam uma proliferação neoplásia de grandes linfócitos, com núcleos formados por cromatina frouxa e nucléolos evidentes (linfomas linfoblásticos). Em

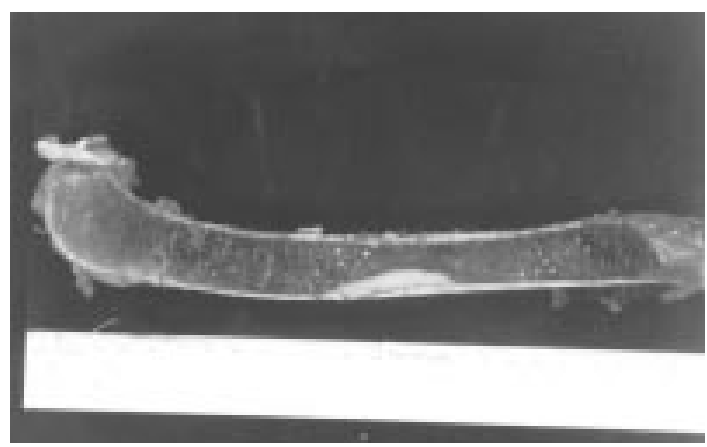

Figura 2 - Massa focal brancacenta no interior da medula óssea (linfossarcoma medular) de um cão com anemia mielotísica. alguns casos, ocorre proliferação de pequenos linfócitos com características atípicas leves (linfomas linfocíticos) (COUTO, 1992; FIGHERA, 2000).

As alterações hematológicas descritas em pacientes caninos com linfossarcoma são bastante inespecíficas e, assim, a realização do hemograma não deve ser encarada como procedimento primordial para se firmar o diagnóstico (JAIN, 1993). Embora muitos autores descrevam a ocorrência de linfocitose nos pacientes afetados, em um trabalho realizado com 72 cães apenas $20 \%$ apresentavam essa alteração, enquanto $25 \%$ desenvolveram linfopenia (JAIN, 1986).

\section{REFERÊNCIAS BIBLIOGRÁFICAS}

ACKERMAN, N., MADEWELL, B.R. Thoracic and abdominal radiographic abnormalities in the multicentric form of lymphosarcoma in dogs. J Am Vet Med Assoc, v.176, p.3640, 1980 .

BAIN, B.J. Tumors of the hematopoietic system. In: FLETCHER, C.D. Diagnostic histopathology ot tumors London : Churchill Livingstone, 1995. 1768p. Cap.22. p.929-957.

BAUER, T. Moléstias mediastínicas, pleurais e extrapleurais. In: ETTINGER, S.J. Tratado de medicina interna veterinária. 3.ed. São Paulo : Manole, 1992. 2557p. Cap.70. p.908-941.

BEDFORD, P.G. Moléstias do focinho e garganta. In ETTINGER, S.J. Tratado de medicina interna veterinária. 3.ed. São Paulo : Manole, 1992. 2557p. Cap.67. p.806-833.

COUTO, C.G. Moléstias dos linfonodos e baço. In: ETTINGER, S.J. Tratado de medicina interna veterinária. 3.ed. São Paulo: Manole, 1992. 2557p. Cap.115. p.2328-2348.

FIGHERA, R.A. Leucemia em medicina veterinária. Santa Maria : O autor, 2000. 47p. Cap.6: Linfoma: p.32-38.

FIGHERA, R.A. Anemia em medicina veterinária. Santa Maria : O autor, 2001. 214p. Cap.7: Anemias por insuficiência medular: p.145-158.

GREENE, C.E. Linfadenopatia. In: LORENZ, M.D., CORNELIUS, L.M. Diagnóstico clínico em pequenos animais. 2.ed. Rio de Janeiro : Interlivros, 1996. 530p. Cap.20. p.117-119.

HARVEY, C.E. Moléstia da faringe e tonsilas. In: BOJRAB, M.J. Mecanismos da moléstia na cirurgia dos pequenos animais. 2.ed. São Paulo : Manole, 1996. 1445p. Cap.62. p.432-434.

HAWKINS, E.C., ETTINGER, S.J., SUTER, P.F. Moléstias do trato respiratório inferior (pulmão) e edema pulmonar. In ETTINGER, S.J. Tratado de medicina interna veterinária 3.ed. São Paulo : Manole, 1992. 2557p. Cap.69. p.855-908.

JAIN, N.C. Schalm's Veterinary hematology. 4.ed. Philadelphia : Lea \& Febiger, 1986. 1221p. Cap.32: The leukemia complex: p.838-908. 
JAIN, N.C. Essentials of veterinary hematology. Philadelphia : Lea \& Febiger, 1993. 417p. Cap.20: The leukemias : p.319348 .

JONES, T.C., HUNT, R.D., KING, N.W. Patologia veterinária. São Paulo : Manole, 2000. 1415p. Cap. 23 : Sistema digestivo : p.1063-1130.

KRUGER, J.M, OSBORNE, C.A Canine and feline hypercalcemic nephropaty. In : OSBORNE, C.A, FINCO

D.R. Canine and feline nefrology and urology. Philadephia : Williams e Wilkins, 1995. 876p. Cap. 21. P.416-440.

LEIFER, C.E., MATUS, R.E., Chronic lymphocytic leukemia in the dog : 22 cases (1974-1984). J Am Vet Med Assoc, v.189, p.214-218, 1986.

MACLACHLAN, N.J., CULLEN, J.M. Fígado, sistema biliar e pâncreas exócrino. In: CARLTON, W.W. Patologia veterinária especial de Thomson. 2.ed. Porto Alegre : Artmed, 1998. 672p. Cap.2. p.95-131.

MAEDA, H., OZAKI, K., HONOGA, S., et al. Hodgkin's-like lymphoma in a dog. Zentralbl Veterinarmed, v.40, p.200204, 1993

MEUTEN, D.J.; ARMSTRONG, P.J. Moléstias da paratiróide e metabolismo do cálcio. In: ETTINGER, S.J. Tratado de medicina interna veterinária. 3.ed. São Paulo : Manole, 1992. 2557p. Cap.94. p.1683-1705.

MOULTON, J.E., HARVEY, J.W. Tumors of the lymphoid and hematopoietic tissues. In: MOULTON, J.E Tumors in domestic animals. 3.ed. Los Angeles : University of California, 1990. 665p. Cap.6. p.231-307.

RAPAPORT, S.I. Hematologia introdução. 2.ed. São Paulo : Roca, 1990a. 450p. Cap.18: Linfomas não Hodgkin: p.239263.

RAPAPORT, S.I. Hematologia introdução. 2.ed. São Paulo : Roca, 1990b. 450p. Cap.19: Doença de Hodgkin: p.264-275.

RICHTER, K.P. Moléstias do intestino grosso. In: ETTINGER, S.J. Tratado de medicina interna veterinária. 3.ed. São Paulo : Manole, 1992. 2557p. Cap.87. p.1462-1486.

SHERDING, R.G. Moléstias do intestino delgado. In:
ETTINGER, S.J. Tratado de medicina interna veterinária 3.ed. São Paulo: Manole, 1992. 2557p. Cap.86. p.1387-1461.

SLATTER, D. Fundamentos de oftalmologia veterinária 2.ed. Buenos Aires : Inter Médica, 1992. 567p. Cap.12: Uvea: p.357-393.

SCOTT, D.W., MILLER, W.H., GRIFFIN, C.E. Muller \& Kirk - Dermatologia de pequenos animais. 5.ed. Rio de Janeiro: Interlivros, 1996. 1130p. Cap.19: Tumores neoplásicos e não neoplásicos: p.926-1054.

THRALL, M.A., MACY, B.W., SNYDER, S.P., et al. Cutaneous lymphosarcoma and leukemia in a dog, resembling Sézari syndrome in man. Vet Pathol, v.21, p.182-185, 1984.

TWEDT, D.C., MAGNE, M.L. Moléstias do estômago. In: ETTINGER, S.J. Tratado de medicina interna veterinária 3.ed. São Paulo : Manole, 1992. 2557p. Cap.85. p.1353-1386.

VALLI, V.E. The hematopoietic system. In: JUBB, K.V., KENNEDY, P.C., PALMER, N. Pathology of domestic animals. 4.ed. San Diego : Academic, 1993. V.3. 653p. Cap.2. p.101-265.

VAN VLEET, J.F., FERRANS, V.J. Patologia do sistema cardiovascular. In: CARLTON, W.W. Patologia veterinária especial de Thomson. 2.ed. Porto Alegre : Artmed, 1998. 672p. Cap.4. p.194-227.

WELLS, G.A. Hodgkin's disease-like lesions in the dog. $\mathbf{J}$ Pathol, v.112, p.5-10, 1974.

WELLMAN, M.L. Neoplasia hematopoética e linfóide. In: BOJRAB, M.J. Mecanismos da moléstia na cirurgia dos pequenos animais. 2.ed. São Paulo : Manole, 1996 1445p. Cap.92. p.737-749.

WHITFORD, E.L. Lymphocytic lymphosarcoma of the canine eye. J Am Vet Med Assoc, v.147, p.837-838, 1965.

WILCOCK, B.P., YAGER, J.A. The behavior of epidermotropic lymphoma in 25 dogs. Can Vet J, v.30, p.754-759, 1989.

WILKINSON, G.T., HARVEY, R.G. Atlas colorido de dermatologia dos pequenos animais. 2.ed. São Paulo: Manole, 1996. 304p. Cap.14: Dermatoses neoplásicas: p.219-242. 